\title{
Amelioration of oxidative and inflammatory changes by Peganum harmala seeds in experimental arthritis
}

\author{
Ashish Singhai ${ }^{1,2}$ (ID and Umesh Kumar Patil ${ }^{3^{*}}$ (D)
}

\begin{abstract}
Background: The present study was designed to investigate the therapeutic effects against oxidative stress and alleviative effects of Peganum harmala seeds (PH) in rats with Complete Freund's Adjuvant (CFA) induced arthritis.

Methods: The extract was evaluated for its phytoconstituents, antiarthritic and antioxidant properties. The action of chloroform (PHC) and ethanolic (PHE) extracts of PH was evaluated in adult Lewis rats (150-200 g).with CFA induced arthritis. Arthritic rats received PH extracts $100 \mathrm{mg} / \mathrm{kg}$ orally for 28 consecutive days (Prophylactic treatment) and from 14th day of CFA injection (Therapeutic treatment).

Results: PHE significantly suppressed the arthritis severity in rats than PHC in 28 days. All complications shown significant reduction $(p<0.05)$ in arthritic rats including paw volume $(63.09 \%)$, body weight loss, decreased locomotor activity, erythrocyte sedimentation rate and synovial/hepatic tissues lipid peroxidation and increase in cellular antioxidants superoxide dismutase $(\mathrm{U} / \mathrm{mg})$ activities and hemoglobin counts. The results showed the presence of alkaloids and flavonoids in PHE. Histology and radiographic analysis of arthritic ankle joints indicated abnormal changes. Marked reduction in inflammation and arthritic changes were observed after treatment with PHE.

Conclusion: Therefore, the investigation suggests that PHE at $100 \mathrm{mg} / \mathrm{kg}$ will be useful in the management of rheumatoid arthritis complications which may possibly be due to boosting the intracellular antioxidant defense.
\end{abstract}

Keywords: Arthritis, Peganum harmala, Antioxidant, Freund's adjuvant, Lipid peroxidation

\section{Background}

Rheumatoid arthritis (RA), a systemic inflammatory autoimmune disease that afflicts $1-2 \%$ of the global population, is characterized by immune-mediated inflammatory sinusitis, which leads to hyperplasia, vasculogenesis, cartilage and bone destruction, joint malformation, functional impairment [1, 2]. Extra- articular complications of RA includes weight loss, oxidative tissue damage, chronic fatigue, and hematological disorders which are associated with the swelling around the joint, pain, abnormal increase in number of synovial cells, morphological changes,

\footnotetext{
* Correspondence: umeshpatil29@gmail.com

${ }^{3}$ Department of Pharmaceutical Sciences, Dr. Harisingh Gour Vishwavidyalaya (A Central University), Sagar M.P.-470003, India

Full list of author information is available at the end of the article
}

and pannus formation [3]. This chronic progressive autoimmune disorder of unknown cause is characterized by pain, swelling and stiffness of synovial joints [4]. The disease affected approximately about $0.75 \%$ in India and $1 \%$ adult population in the world and the responsible causative factors for the development of it are unknown [5].

An inflammatory reaction, imbalance between proinflammatory and anti-inflammatory state, increased cellularity of synovial tissue, joint inflammation and joint damage are the pathological hallmarks of RA [6-8]. The other most common extra-articular complication in RA is anemia [9]. Extra-articular can also be considered as a predictor of mortality in patients with RA [10];

These complications arose throughout the onset of disease and its progression which are mostly related to 
excessive inflammation and cellular oxidative stress induced by inflammatory mediators and free radicals, respectively [11]. The detrimental effects of reactive oxygen species (ROS) and nitrogen species (RNS) like free radicals on synovial joint and vital organs is also evident and have potential role in development of RA. Those complications can be reduced by scavenging the free radicals by anitoxidants and ameliorating the radicals $[12,13]$.

The treatment strategy for the disease involves the use of non-steroidal anti-inflammatory drugs (NSAIDs), disease modifying anti-rheumatic drugs (DMARDs), immunomodulators, biological agents and corticosteroids. This conventional approach has shown effective results with ameliorating symptoms but the adverse effects cannot be neglected [14]. However, despite an increase in use, evidence for effectiveness and safety of other complementary therapies with them is limited [15].

Peganum harmala $(\mathrm{PH})$, also known as harmala or Syrian rue, is an herbaceous perennial plant of the family Nitrariaceae; is used as a traditional herbal remedy for various diseases [16].

In traditional medicine, it has been used for the treatment of different conditions, like asthma, lumbago, colic, jaundice and to stimulate menstrual flow. However, in recent pharmaceutical studies, $\mathrm{PH}$ found to have an antispasmodic, antimicrobial, emmenaguage and abortive effects, blocking different types of intestinal calcium channels, mono amine oxidase inhibition and antidepressant effect, analgesic [17].

The beta carboline alkaloids, also called as harmal alkaloids (e.g. harmalol, harmine, harman and harmaline) and quinazoline alkaloids (vasicine and vasicinone) have potent pharmacological action [18]. They are mainly present in seeds of $\mathrm{PH}$ and are responsible for $\mathrm{PH}$ toxicity. The drug also shows antidepressant action by competitively and reversibly inhibiting the monoamine oxidases (MAO). Therefore, the present study aimed to evaluate the alleviative effects (from the day of arthritis induction and arthritis onset) of $\mathrm{PH}$ extracts on articular/ extra- articular complications (with special reference to cellular oxidative stress and anemia) in rats with CFA induced arthritis.

\section{Material and method}

\section{Instruments and chemicals}

Diclofenac sodium, Complete Freund's adjuvant was obtained from Sigma Aldrich Chemical Co., Bengaluru, EDTA (Merck Laboratories Pvt. Ltd.), DTNB (Tokyo Chemical Industry Co. Ltd.), Thio-Barbituric Acid, Trichloro acetic Acid (Sunchem India). All other chemicals used in the study were of analytical grade. Cooling centrifuge (Remi-electrotechnic limited), UV Spectrophotometer (Pharmaspecs shimadzu), Actophotometer
(Teknik), Hot plate (Lyzer India), Rotatory Flash Evaporator (IKA RV10), trinocular microscope, and other instruments were used.

\section{Plant material and extraction procedure}

The plant and seeds was collected from Mulla Mukhtar Husain Gulam Abbas, Jumerati Bazar, (M.P.) where it is used for commercial and medicinal purposes. The plant was authentified from Department Of Botany at Safia Science College, Bhopal (M.P.) by Dr. Zia Ul Hasan with a voucher Specimen no. 316/Bot/Safia/12.

The seeds were cleaned, dried in the shade so as to protect its chemical constituents not to get degrade at high temp. The moderately coarse powder of the $\mathrm{PH}$ seeds was subjected to successive soxhlet extraction by petroleum ether, chloroform, ethanol and water (Fig. 1). The last traces of solvent being removed under vacuum by rota-vaccum evaporator. The extracts obtained were weighed to a constant weight and percentage $\mathrm{w} / \mathrm{w}$ basis was calculated and stored in cool dry place in airtight container for further use [19].

\section{Phytochemical analysis}

The extracts were subjected to phytochemical analysis for identification of alkaloid, saponin, tannins, phenolic compounds, carbohydrates, flavonoids, triterpenes and steroid detection according to method described by Harborne [20]. The chloroform extract of $\mathrm{PH}$ (PHC) and ethanolic extract of $\mathrm{PH}$ (PHE) extracts were selected for further studies after preliminary screening.

\section{Animals}

The experiment was carried out on healthy albino Lewis rats of either sexes weighing between 200 and $250 \mathrm{~g}$. were used for the evaluation of acute oral toxicity test and anti arthritic activity. Animals were provided by the authorized animal house of Sapience Bioanalytical Research Lab, Bhopal, Madhya Pradesh, India. The animals were used after an acclimatization period of 10 days to the laboratory environment. The experiment was approved by the Institutional Animal Ethical Committee as per the committee for the, Purpose of control and supervision of experiments on animal's guideline. (CPCSEA Reg. no.: 1413/PO/a/11). All animals were kept in standard cages and maintained at $25^{\circ} \mathrm{C}$. Under $12 \mathrm{~h}$ dark/ light cycle. The animals were fed with standard rat feed and water was given after specific interval prior to experiment animal were kept for $12 \mathrm{~h}$ fasting.

\section{Experimental design}

\section{Acute oral toxicity study and selection of doses}

Oral dose of PH was determined through the acute oral toxic test in rats by Irwin Battery test at different doses. The dose level to be used as the starting dose is selected 


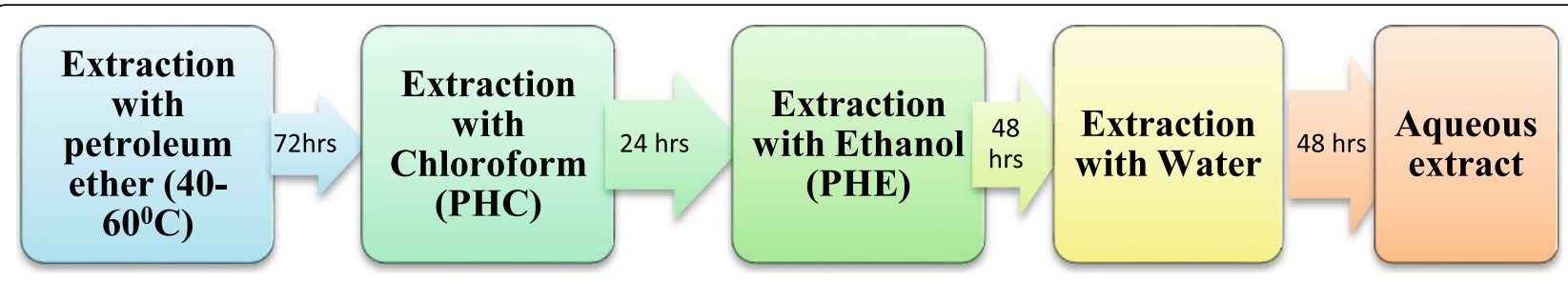

Fig. 1 Successive solvent extraction procedure for Peganum harmala seeds

from one of four fixed levels, 5, 50, 300 and $2000 \mathrm{mg} / \mathrm{kg}$ body weight.

\section{Induction of arthritis}

Lewis rats of either sex weighing $180 \pm 20 \mathrm{~g}$ was divided into seven groups of six animals each. Group I served as control (without treatment), Group II served as arthritic control (negative control), Group III was treated with Diclofenac sodium (positive control) (in 0.5\%) the standard anti-arthritic control, Group IV received chloroform extract of Peganum harmala (PHC), Group VI received alcoholic extract of Peganum harmala (PHE) extract for 28 days from the induction day (0-28 days treatment), Group V and VII received chloroform extract of Peganum harmala (PHC) and alcoholic extract of Peganum harmala (PHE) for 14 days from the 14th day of induction (14th to 28th day treatment). The body weight changes were observed on every week. (Table 1).

Arthritis was induced in rats by the injection of $100 \mu \mathrm{l}$ of Complete Freund's Adjuvant (CFA) into the sub plantar region of hind paw of the rats [21]. On 29th day, at the end of experiment, all animals were sacrificed by cervical decapitation and blood was collected in plain and EDTA containing tubes.

Table 1 Grouping of animals

\begin{tabular}{|c|c|c|}
\hline S. No. & Group & Details \\
\hline 1. & Group I as control (GI) & $\begin{array}{l}\text { Sod. CMC } 0.5 \% \mathrm{w} / \mathrm{v} \text { in distilled water } \\
5 \mathrm{ml} / \mathrm{kg}, \text { p.o }\end{array}$ \\
\hline 2. & $\begin{array}{l}\text { Group II as Arthritic } \\
\text { control (GII) }\end{array}$ & $\begin{array}{l}\text { Mycobacterium butyricum in paraffin } \\
\text { oil } 10 \mathrm{mg} / \mathrm{ml}\end{array}$ \\
\hline 3. & $\begin{array}{l}\text { Group III as standard } \\
\text { drug (GIII) }\end{array}$ & $\begin{array}{l}\text { Diclofenac sodium suspended in } 0.5 \% \\
\text { w/v sodium CMC, mg/ } \mathrm{kg} \text { p.o. }\end{array}$ \\
\hline 4. & Group IV as test (GIV) & $\begin{array}{l}100 \mathrm{mg} / \mathrm{kg} \text { p.o. body weight of } \\
\text { chloroform extract of Peganum harmala } \\
\text { seeds (PHC) for } 28 \text { days. (Treatment-1) }\end{array}$ \\
\hline 5. & Group V as test (GV) & $\begin{array}{l}100 \mathrm{mg} / \mathrm{kg} \text { body weight of chloroform } \\
\text { extract of Peganum harmala seeds for } \\
\text { (PHC) } 14 \text { days (Treatment-2) }\end{array}$ \\
\hline 6. & Group VI as test (GVI) & $\begin{array}{l}100 \mathrm{mg} / \mathrm{kg} \text { body weight of ethanolic } \\
\text { extract of Peganum harmala seeds } \\
\text { for (PHE) } 28 \text { days (Treatment-3) }\end{array}$ \\
\hline 7. & Group VII as test (GVII) & $\begin{array}{l}100 \mathrm{mg} / \mathrm{kg} \text { body weight of ethanolic } \\
\text { extract of Peganum harmala seeds } \\
\text { (PHE) for } 14 \text { days (Treatment- } 4 \text { ) }\end{array}$ \\
\hline
\end{tabular}

\section{Arthritic assessment}

To follow the course of the disease, swelling of the hind paw was determined with vernier calipers and body weight was measured by electronic weighing balance. The paw volume was periodically measured on 0 th, 7 th, 14th, 21st and 28th day (after injection of CFA) thereafter to confirm the reduction of RA. The locomotor activity was determined [22].

\section{Hematological and biochemical assessment}

Hemoglobin was measured in rat blood by the Erba auto analyzer before and after the induction of arthritis. After treatment with the standard and various extracts hemoglobin was measured and compared with the control group.

Blood was withdrawn on the day 7,14,21,28 from every rat through the orbital puncture into a blood collecting tube to measure erythrocyte sedimentation rate (ESR). The ESR was determined by the method of Huxtable [23]. The antioxidant parameters superoxide dismutase (SOD) and lipid peroxidation (LPO) was estimated in plasma by enzymatic testing kits [24].

\section{Histological and radiographic studies}

For histopathology, the proximal interphalangeal joints were removed, washed with saline and stored in $10 \%$ formalin on 29th day from two animals per group. The interphalangeal joints sections were obtained stained with eosin-haematoxylin stain and viewed under $100 \mathrm{X}$ magnifications. The hind (arthritis induced) legs of the experimental rats were taken for X-ray, and examined for soft tissue swelling, bony erosions and narrowing of the spaces between joints.

\section{Statistical analysis}

The results were expressed as the mean \pm standard error mean of the mean of 6 animals for each group. Statistical differences were evaluated using a One-way analysis of variance (ANOVA) followed by Dunnett's test. Results were considered to be statistically significant at $p<0.05$ (or less). 


\section{Results}

Morphological analysis

Morphological features help in identification and confirmation of crude herbal drugs. The seeds are 3-4 mm in diameter, brown in color and triangular or conical in shape with micropyle at tip. (Fig. 2).

\section{Preliminary phytochemical screening}

Following percentage yield was obtained after successive solvent extraction of $\mathrm{PH}$ seeds: (Table 2).

Preliminary phytochemical tests had shown that petroleum ether extract contains fats; chloroform extract contains alkaloids, proteins and flavonoids. Ethanolic extract showed alkaloids, carbohydrates, phenolic compounds and flavonoids. Aqueous extracts has shown the presence of carbohydrates and phenolic compounds. The chloroform (PHC) and ethanolic extracts (PHE) were selected for further studies.

\section{Modulatory effect of PHC and PHE on hind paw volume} The paw volume of the hind paws was measured by Vernier calipers on day 0,7,14, 21 and 28th day of the experiment. Erythema and edema were the inflammatory signs that developed over a $24 \mathrm{~h}$ period and increase thereafter in the present study in hind paws injected with CFA. The arthritic inflammation was significantly decreased $(p<0.01)$ in arthritic rats treated orally from 0 day with $\mathrm{PH}$ extracts compared with those receiving vehicle and negative control (Figs. 3 and 4). Treatment group 3 has significant reduction in inflammation $(p<$ 0.001). All treatment groups of PHE extract shown marked decrease in arthritic inflammation $(p<0.01)$. The PHE extract $(0.31 \pm 0.06)$ was more effective than $\mathrm{PHC}$ $(0.34 \pm 0.04)$ in mean changes in paw volume in 28 days. The effect of $\mathrm{PH}$ extracts on hind paw volume as percentage inhibition was in following order: GVI (63.09\%) $>$ GVII (61.90\%) > GIV (60.71\%) > GV (59.52\%).

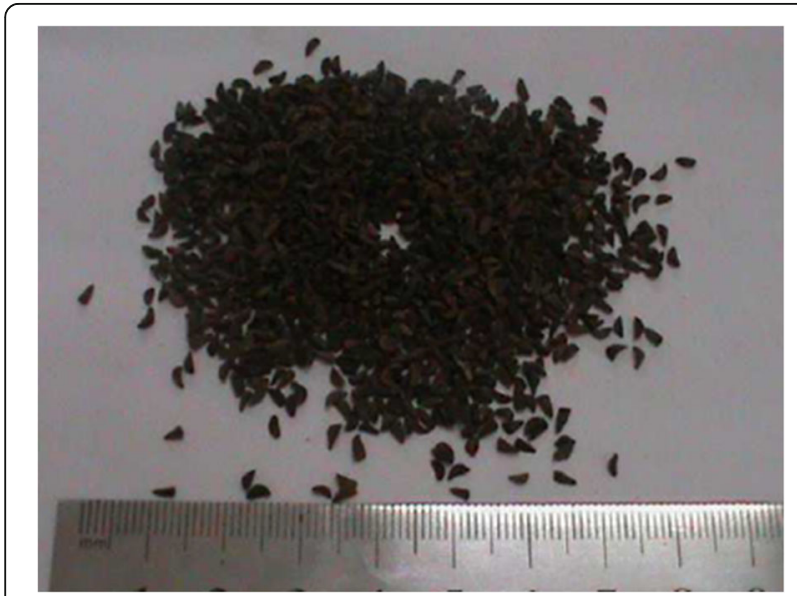

Fig. 2 Peganum harmala seeds
Table 2 Percentage yield of PH extracts

\begin{tabular}{llll}
\hline S.No. & Solvent & Extract color & \% Yield w/w \\
\hline 1 & Petroleum ether & Greenish Black & 3.54 \\
2 & Chloroform & Dark green & 2.98 \\
3 & Ethanol & Brownish Black & 12.45 \\
4 & Water & Brownish Black & 6.75 \\
\hline
\end{tabular}

\section{Modulatory effects of PHC and PHE on body weight changes}

The present study showed that inflammatory consequences in arthritic joints have an impact on weight loss and it correlates with the extent of joint inflammation to the grade of weight loss. With the induction and progression of arthritis after one week of adjuvant injection, significant weight loss was observed in the arthritic rats, which get reduced in subsequent weeks. The treatment group ( $1^{\text {st }}$ group) and standard drug treated groups showed less weight loss. (Fig. 5) PHE (GVIand GVII) and PHC (GV) significantly alleviated $(p<0.05)$ and GIII $(p<0.001)$, the body weight loss of arthritic rats during the treatment course. The improvement of body weight gain of arthritic rats by $\mathrm{PH}$ extracts from day 0 was concomitant with food intake.

\section{Modulatory effect of PHC and PHE on Locomotor activity}

Locomotor activity of all animals was assessed during experiment on the day of $0,7,14,21$ and 28th day with the help of Actophotometer instrument. The PH extracts and standard drug shown significant improvement $(p<0.001)$ on 21 st and 28th day, in the movement of rats which indicates the recovery in arthritic complications (Fig. 6). PHE extract was more effective than PHC and showed alleviative effect in 28 days.

\section{Modulatory effects of PHC and PHE on hemoglobin content}

On the day $0,7,14,21$ and 28th day of experiment hemoglobin content was observed and significant elevation in $\mathrm{Hb}$ content was observed in arthritic rats when compared with others group rats (Fig. 7). $\mathrm{Hb}$ content was significantly decreased by $14.34 \pm 0.58$ to $12.84 \pm 0.07$ in arthritic rats. The $\mathrm{PH}$ extracts significantly alleviated anemic condition in arthritic rats when given from 0 to 28 days. This alleviative effect of $\mathrm{PHC}$ was comparative with the standard drug and greater than the PHE. The PHC and standard drug shown more significant results than PHE when compared with arthritic control $(p<0.001)$. The $\mathrm{Hb}$ content observed in 28 days in different groups was: GII $(12.84 \pm 0.07)<\mathrm{GV}<\mathrm{GVII}<\mathrm{GVI}<\mathrm{GIV}<\mathrm{GIII}<\mathrm{GI}$ $(14.47 \pm 0.16)$. 

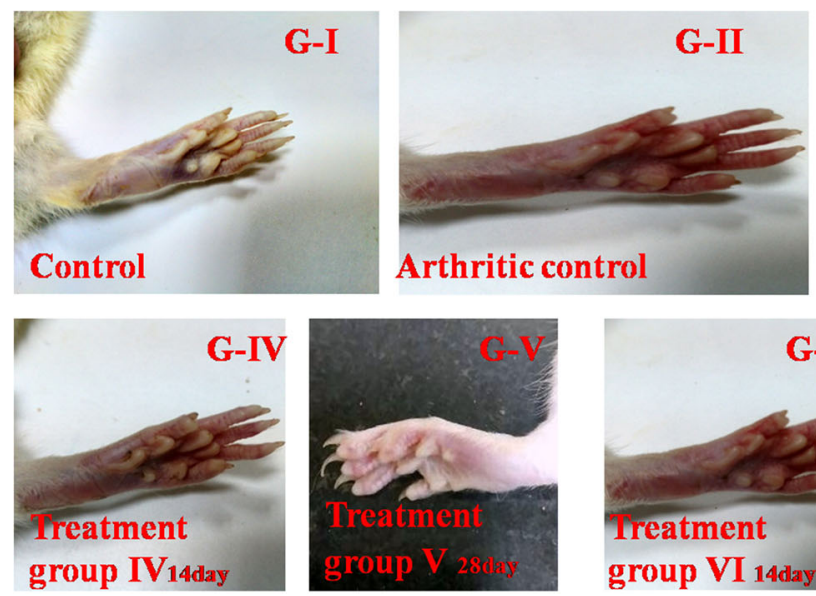

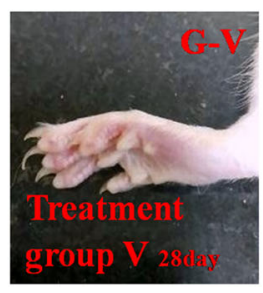

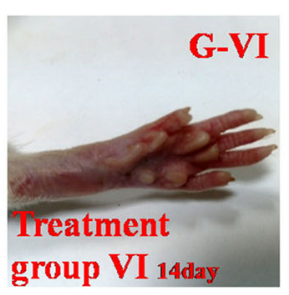

G-VI

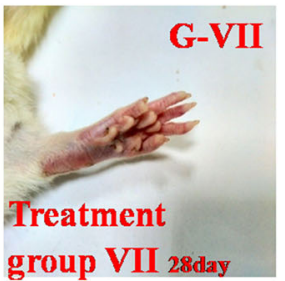

Fig. 3 CFA induced inflammation in rats

\section{Modulatory effects of PHC and PHE on ESR}

ESR was significantly decreased with both group of PHE treatment as compared to vehicle treated arthritic rats and PHC treated groups. There was decrease in the levels of ESR from 8.4 to $7.5 \mathrm{~mm}$ per hour $(\mathrm{mm} / \mathrm{h})$ in group VI and 8.7 to $8.0(\mathrm{~mm} / \mathrm{h})$ in group VII of PHE treated groups $(p<0.05)$. There is significant increase in ESR levels in negative control group from 4.2 to 13.8 . (Fig. 8).

\section{Modulatory effects of PHC and PHE on oxidative stress}

In Treatment groups (GIII, GVI and GVII) SOD level elevated significantly as compared to negative control groupII. However, lipid peroxidation significantly reduced which was measured in the form of MDA in liver.
This reduction in MDA level (an indicator of LPO) was statistically significant $(p<0.001)$ as compared to arthritic control group of rats (Figs. 9 and 10). PHE (204 \pm 0.09) was more effective than PHC $(196.1 \pm 0.01)$ when compared with the healthy control rats on 28 th day. The level of SOD were found to be significantly decreased $(p<0.001)$ in arthritis rats $(81 \pm 0.05)$ compared to control group $(272.60 \pm 0.04)$. On the contrary, Peganum harmala treatment to arthritis rats showed a significant increasing effect in superoxide dismutase levels in developing phase $(\mathrm{p}<0.001)$.

The level of lipid peroxidation (MDA) were found to be significantly increased $(\mathrm{p}<0.001)$ in arthritis rats $(108.4 \pm 0.35)$ compared to the normol control rats $(28.7$ \pm 0.11 ) and decreased in GVI and GVII (PHE treated).

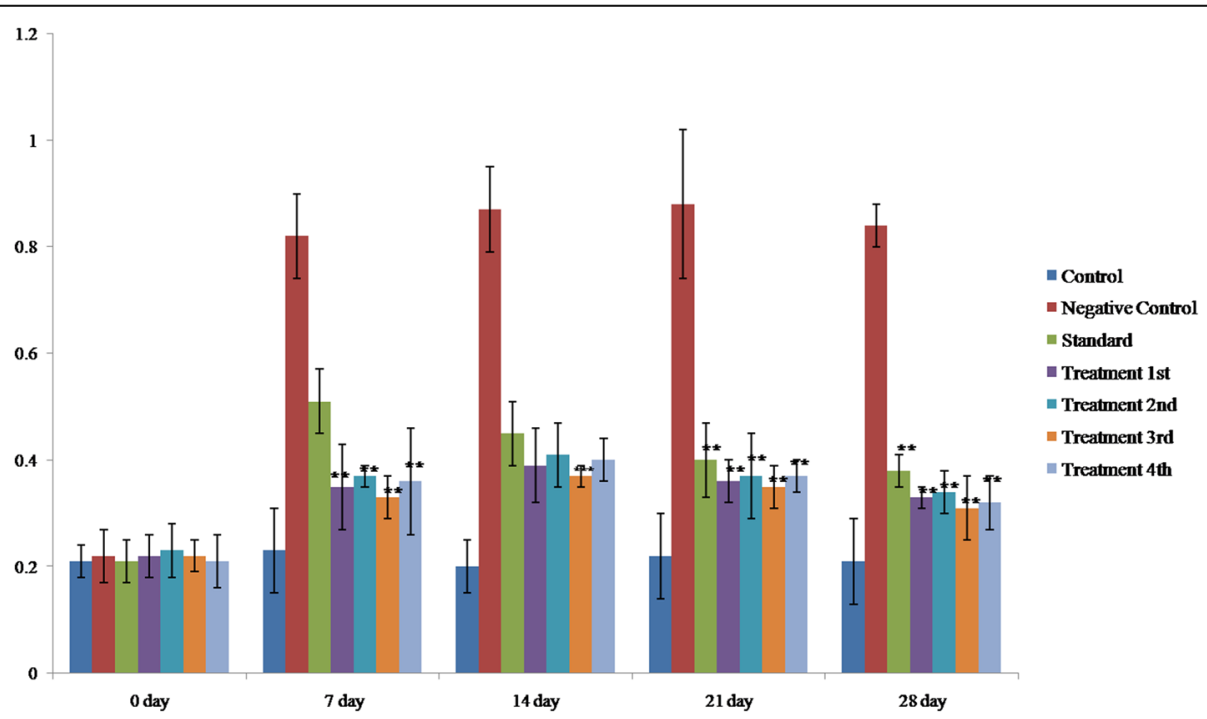

Fig. 4 Effect of PH extracts on mean change in paw volume. Values are Mean \pm S.E.M, $n=6$ animals in each group. Results are Mean \pm S.E.M. ANOVA, Dunnett's test ${ }^{* * *} p<0.001,{ }^{* *} p<0.01$ (treated groups Vs arthritic control group II) 


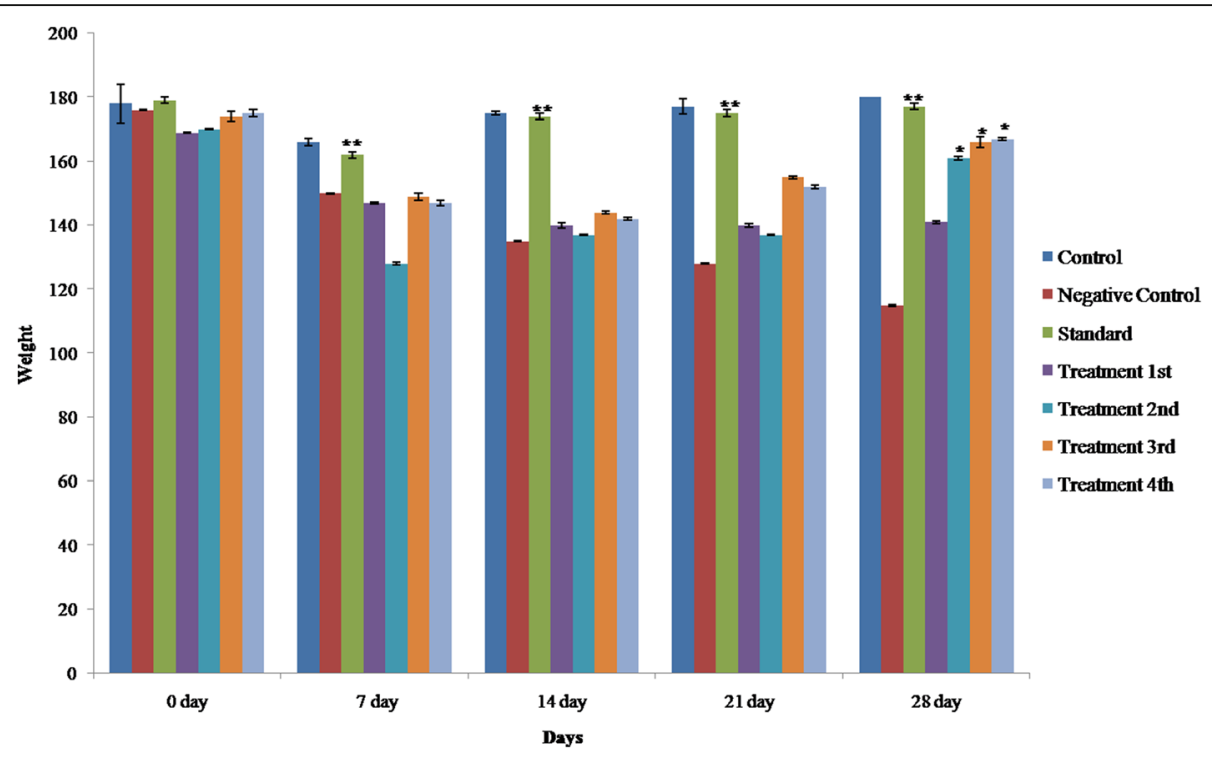

Fig. 5 Effect of PH extracts on weight of animals. Results are Mean \pm S.E.M, $n=6$ animals in each group. ANOVA, Dunnett's test ${ }^{* *} p<0.001$, ${ }^{*} p<$ 0.05 compared with arthritic control group

On the contrary, Peganum harmala treatment to arthritis rats showed a significant lowering effect in lipid peroxidation levels in developing phase (42.1 \pm 0.01$)$ (Fig. 10).

\section{Radiology of hind paw after 28 day of induction of CFA}

Radiological imaging is a useful tool which helps to understand the severity of the disease. In these studies there was no deformities observed in ankle joint whereas in negative control bony destruction, soft tissue welling and narrowing of the joint spaces was observed. (Fig. 11a-g) Group received standard drug had prevented this bony destruction and there is minor swelling of the joint, Treatment 1 st to 4 th groups have no bony destruction and also there is no swelling of the joint. Treatment-III (GVI) and Treatment-IV (GVII) group has shown significant prevention against bony destruction by showing less soft tissue swelling and narrowing of joint spaces when compared with

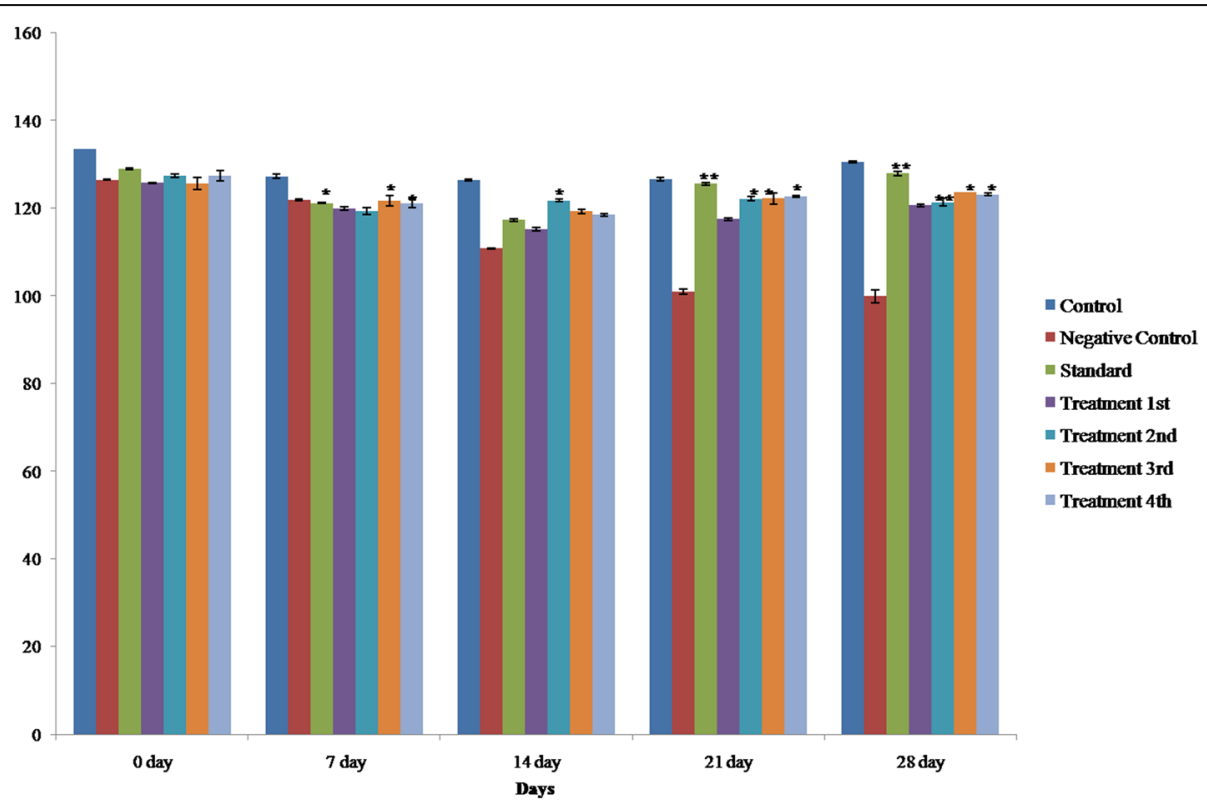

Fig. 6 Effect of PH extracts on Locomotor Activity. Results are Mean \pm S.E.M, $n=6$ animals in each group. ANOVA, Dunnett's test ${ }^{* *} p<0.001,{ }^{*} p<$ 0.05 compared with arthritic control group 


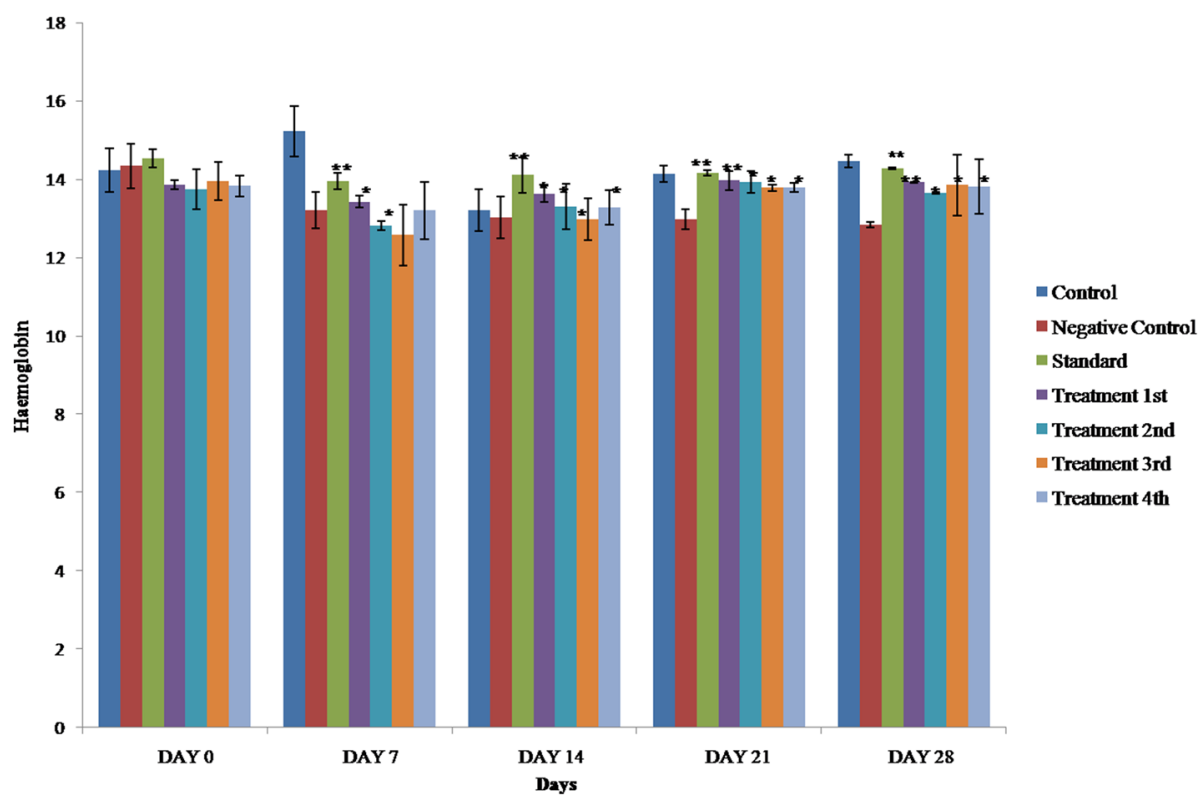

Fig. 7 Effect of PH extracts on hemoglobin content. Results are Mean \pm S.E.M, $n=6$ animals in each group. ANOVA, Dunnett's test ${ }^{* *} p<$ $0.001, * 0<0.05$ compared with arthritic control group

Treatment II (GV), I (GIV) and negative control group (GII).

\section{Histopathology of joints}

The sections of proximal interphalangesal joints collected from the experimental rats were studied to observe the histopahtological changes. (Fig. 12a-g) The degree of pannus formation, synovial hyperplasia and erosion of bone and cartilage were observed. The rats of group-II (neagative control) showed edema formation, synovial hypeplasia and degeneration of cartilage. The infiltration of inflammatory exudates in articular region with bone marrow destruction and pannus formation was also observed,when compared with the normal control group (Group-Ia). The test groups (group VI and VII) (Fig. 12f and g) showed protective effect as less inflammatory features were observed after 28 days treatment. But are comparable to the standard drug treated group III (c) showing normal bone marrow and lesser inflammatory

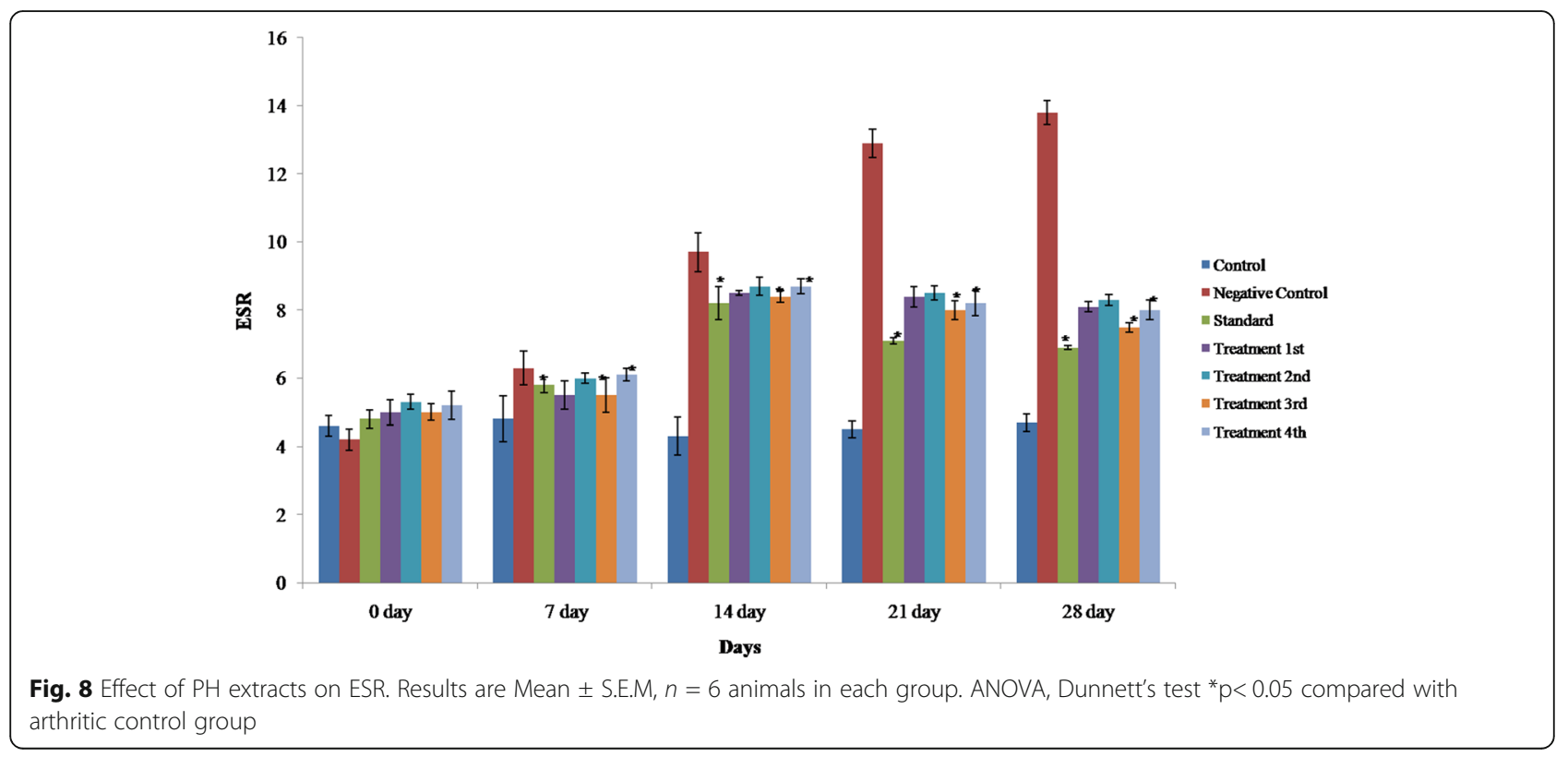




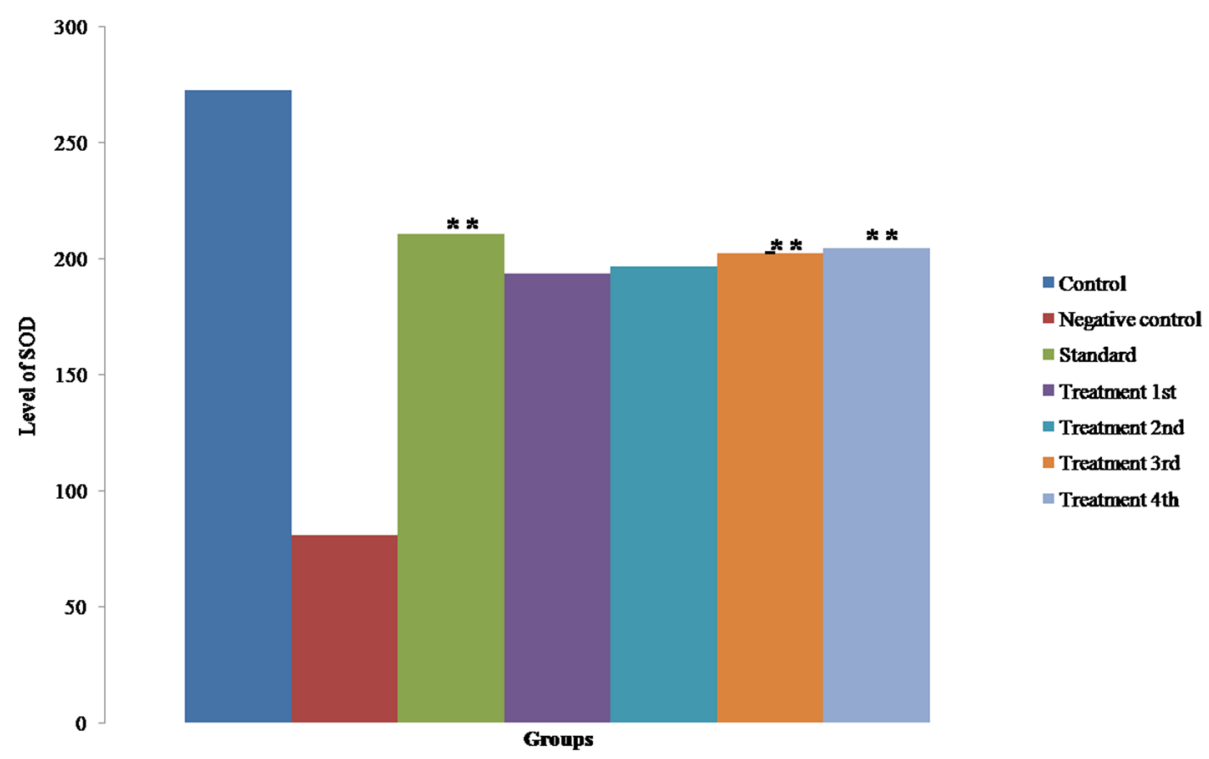

Fig. 9 Effects of PH extracts on SOD activity. Results are Mean \pm S.E.M, $n=6$ animals in each group. ANOVA, Dunnett's test ${ }^{* *} p<0.001$ compared with arthritic control group

exudates. The small quantity of cellular infiltrates, normal bone marrow and absence of edema formation in the test groups exemplifies their preventive role for inflammatory responses. The test drug treated both groups prevent the ankle joint from degeneration, comparative to the negative control group.

\section{Discussion}

Adult population suffering from RA is around 1\% worldwide in which the causative factor is unknown and pathogenesis is poorly understood [25, 26]. The inflammatory mediators released in arthritis are responsible for the pain, destruction of bone and cartilage that affects the movement of $80 \%$ suffering persons and adversely affects their quality of life. Arthritis induced with an antigenic solution of CFA stimulates cellular mediators and potentiates the production of certain immunoglobulins. This makes it beneficial in evaluating drugs for RA treatment as well as for assessing the anti-arthritic potency and anti-inflammatory potential

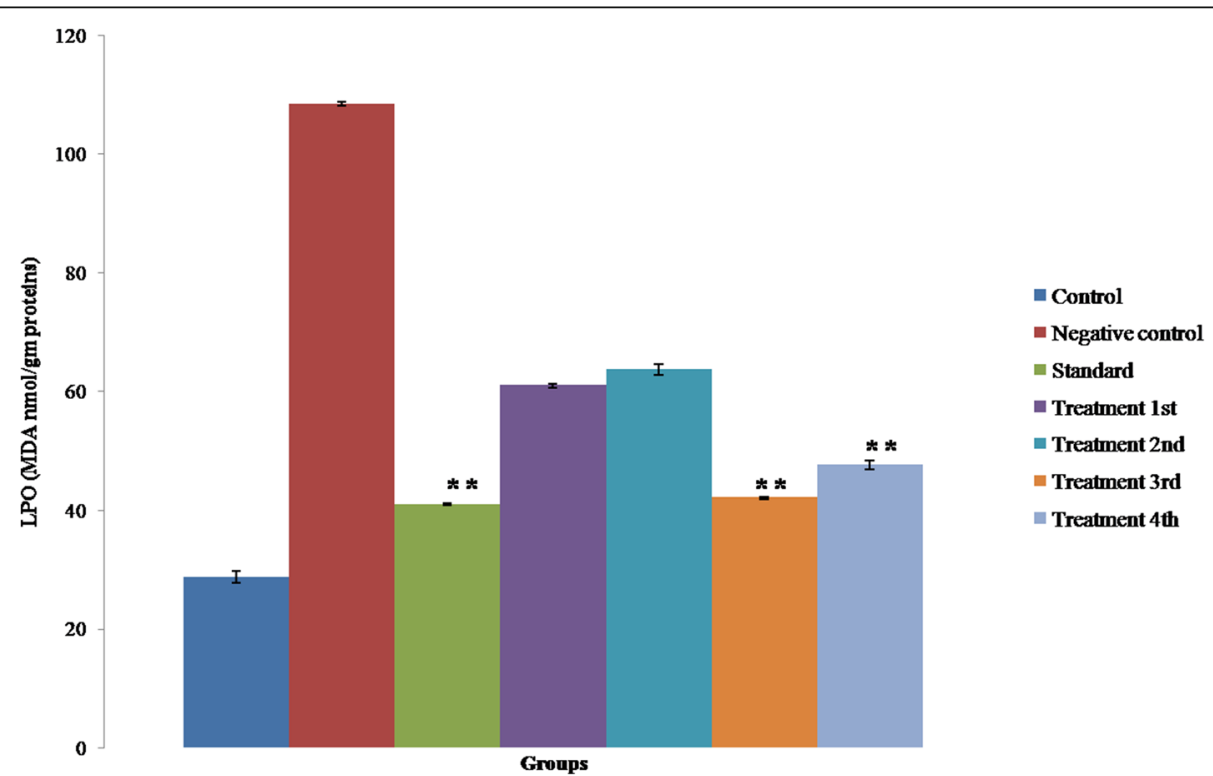

Fig. 10 Effects of PH extracts on LPO activity. Results are Mean \pm S.E.M, $n=6$ animals in each group. ANOVA, Dunnett's test ${ }^{* *} p<0.001$ compared with arthritic control group 

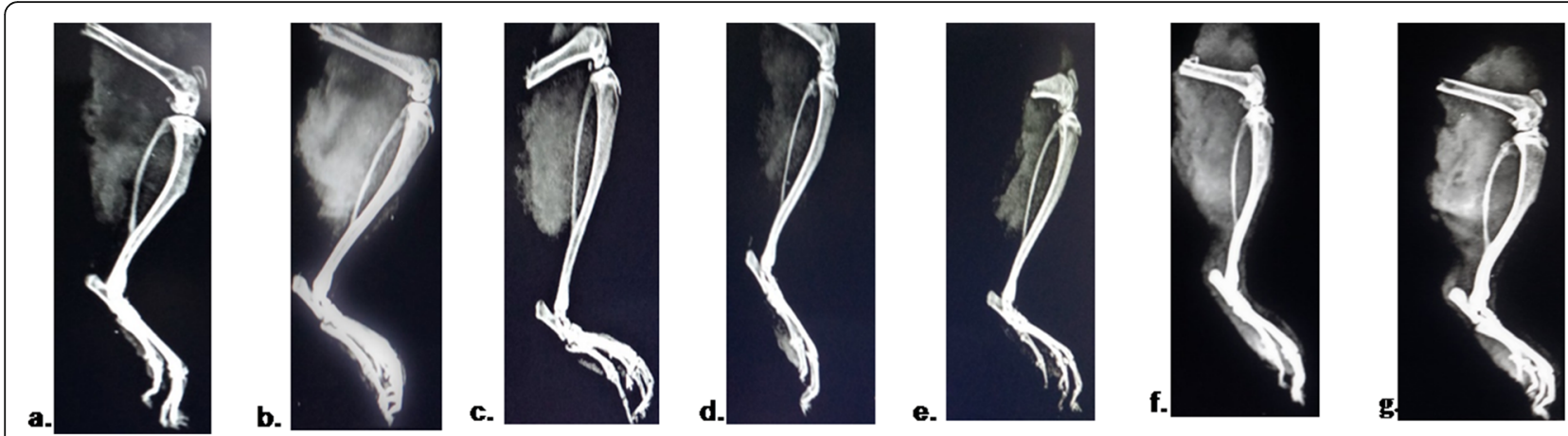

Fig. 11 Radiology of Hind Paw for various treatment groups: Where a. Normal Control (Gl), b. Negative Control (GII), c. Standard group (GIII), d. Treatment-I (GIV), e. Treatment-II (GV), f. Treatment-III (GVI), g. Treatment-IV (GVII)

of drugs [27]. This model in rats closely mimics the clinical features of human RA which makes it appropriate for evaluation [28].

The extent of inflammation in CFA induced rats is measured as swelling in paw represented by an index. Reduction in paw swelling is used as an indicator for the antiarthritic potential of various drugs [29, 30], it was employed to determine the activity of $\mathrm{PH}$ extracts at the dose level $100 \mathrm{mg} / \mathrm{kg}$ p.o. Groups received PH extracts showed significant reduction in paw volume especially PHC than PHE when compared with the arthritic control group (Fig. 3-4). The alleviative effect of PH extracts (from zero day) on paw edema in arthritic rats may be due to its inhibitory action on the release of proinflammatory cytokines [e.g. tumor necrosis factor $($ TNF- $\alpha$ ) and interlukin (IL-1 $\beta$ )]. Those mediators affect the release of free radicals and other inflammatory mediators such as $\mathrm{NO}$ and prostaglandin $\left(\mathrm{PGE}_{2}\right)$ via specific enzymes [29]. In the present investigation, $\mathrm{PH}$ extracts specially the PHE showed significant reduction in paw edema.

The decrease in weight gain may be due to appetite loss, the decrease in intestinal absorption capacity (arising from intestinal oxidative damage), and/or metabolic disorders resulting from excessive release of systemic pro-inflammatory mediators and free radicals (rheumatoid cachexia) (Fig. 5) [31, 32]. This was observed in negative control arthritic rats. The improvement in body weight gain is a good and simple indicator for arthritis recovery during the treatment course of CFA in rat models. The result of present investigation reveals the potential of $\mathrm{PH}$ extracts in protecting against the weight loss in arthritic conditions.

In present study the rats received $\mathrm{PH}$ extracts showed significant activity in actophotometer. It may be due to the immunomodulation effect of $\mathrm{PH}$ extracts. As there is

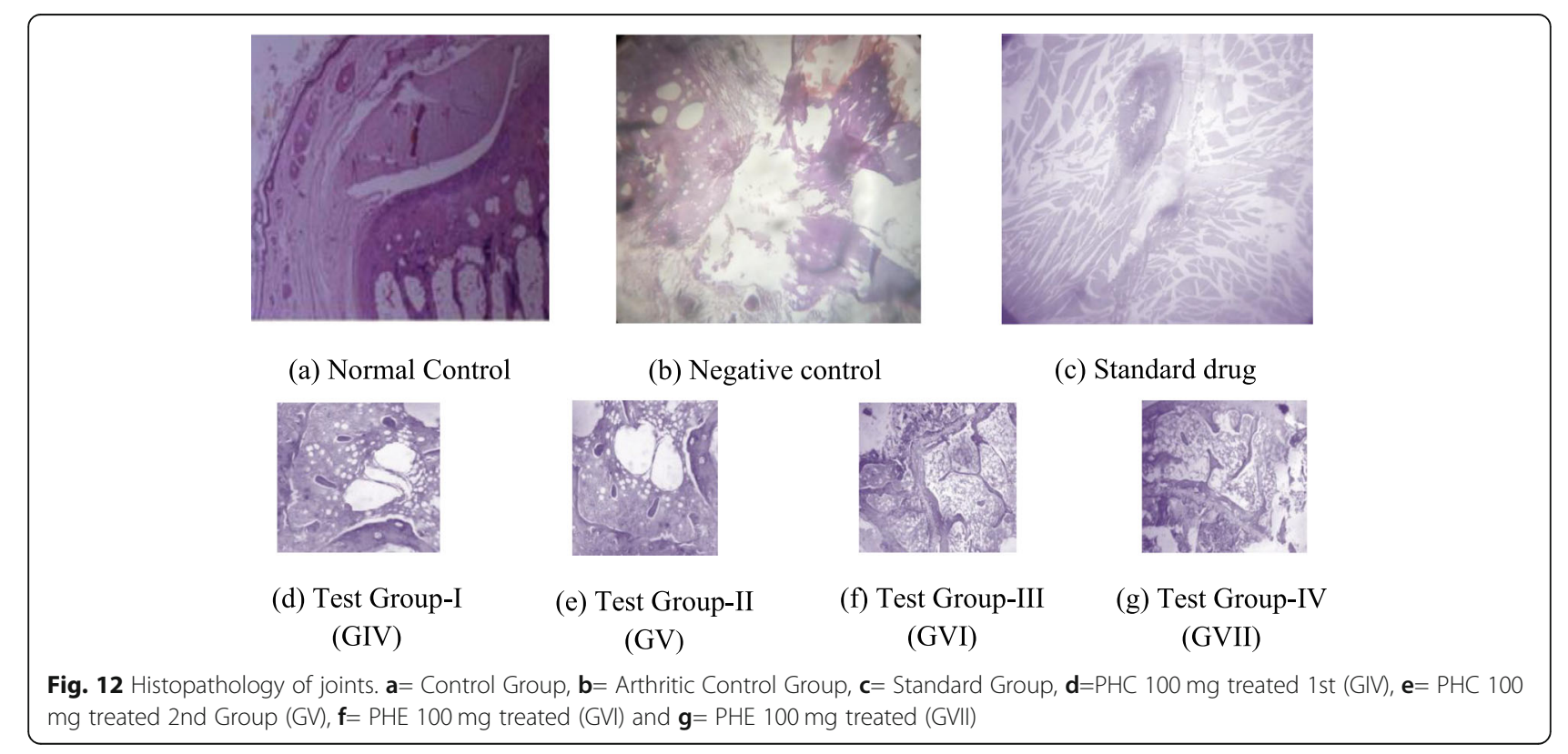


significant decrease in locomotors count in CFA induced arthritic rats and this may be due to the stimulation of immune system against the invading antigens [33]. The lesser movement of activity of animals in actophotometer especially in arthritic groups was due to the stiffness and pain in joints. (Fig. 6).

Results of blood examinations e.g. haemoglobin, white blood cell count and pack cell volume reveals the functioning of bone marrow [34]. In our investigation on hemoglobin count in CFA induced rats, haemoglobin level was decreased in arthritic rats which represents the anemic condition. This was supported by reports on similar arthritis model. This may due to the two reasons, abnormal storage of iron in the reticuloendothelial system and synovial tissue, and the failure of bone marrow to respond to anemia [35] (Fig. 7). The hematological changes in arthritic rats indicated anemia which may be due to gastrointestinal bleeding (due to oxidative damage of gastrointestinal bleeding) and/or inhibition of bone marrow erythropoiesis synthesis by pro-inflammatory cytokines, especially TNF- $\alpha$, IL- $\beta$ and IL-6) [36]. The PH extracts especially PHE significantly alleviated the condition in arthritic rats.

The increase in ESR count is a clinical feature of chronic arthritic conditions. In our study $\mathrm{PH}$ extracts especially PHE after 28 days shown significant results by improving the conditions when compared to negative control group. PH extracts and standard drug counteracted on the increased ESR in arthritic rats and improved the conditions. (Fig. 8).

In RA conditions the reactive oxygen species are produced (especially superoxide anion and hydroxyl radicals) by phagocytic cells due to inflammatory events, which results in decrease in cellular antioxidants. During oxidative stress membrane lipid peroxidation and lysosomal destruction causes cellular lysis and supersaturation of antioxidants depletes them. The elevated level of myeloperoxidase (MPO) and MDA causes oxidative damage of the gut mucosal membrane [37]. In our present investigation the levels of MDA (an end product of peroxidized lipid decomposition) was increased significantly in CFA treated rats as compared to control rats. Treatment with PHE resulted in significant reduction in MDA levels in plasma whereas the SOD level is increased in rats. Excessive oxidative stress (ROS) could damage the synovial fluid and joint collagen by depleting SOD through oxygen radicals [38]. However administration of PHE to arthritic rats resulted in a significant increase in SOD activity and reduces the LPO level near to normal control rats which show ROS scavenging or antioxidant property. (Figs. 9 and 10) The phytochemical screening of PHE revealed the presence of alkaloids, carbohydrates, phenolic compounds and flavonoids. The presence of alkaloids, flavonoids and phenolic compounds may be responsible for antioxidant and antiinflammatory action.

The histological architecture of rat joints was found normal in histological studies. The $\mathrm{PH}$ treated both groups and standard drug has shown protective effect on the joint structure. They tend to ameliorate the normal histological architecture with cartilage protection. The overall prevention of the inflammatory signs of the rat ankle joints was significant in 28 days drug treated group compared with 14 days drug treated group. Degeneration of the ankle joint was not observed in any of the drug treated groups when compared with the negative control. (Fig. 12).

Radiological studies also supported the anti-arthritic activity of PH. PHE treatment for 28 days have shown significant prevention against bony destruction by showing less soft tissue swelling and narrowing of joint spaces when compared with 14 days PHE treated group.

\section{Conclusion}

PHE at the dose of $100 \mathrm{mg} / \mathrm{kg}$ has a significant therapeutic effect than PHC in alleviating the articular/ extraarticular oxidative damage in CFA induced rat model especially when the treatment started from the day of arthritis induction. The presence of alkaloids and flavonoids might have potentiated the anti oxidant and anti arthritic activity. Further, experimentation is required for characterization and quantitative determination of bioactive phyto-constituents which are responsible to maintain the therapeutic efficacy.

\section{Supplementary Information}

The online version contains supplementary material available at https://doi. org/10.1186/s40816-020-00243-3.

\section{Additional file 1.}

\section{Abbreviations \\ CFA: Complete Freund's Adjuvant; PH: Peganum harmala; PHC: Chloroform extract of PH; PHE: Ethanolic extract of PH; RA: Rheumatoid arthritis; ROS: Reactive oxygen species; RNS: Reactive Nitrogen species; NSAID's: Non- steroidal anti-inflammatory drugs; DMARD's: Disease modifying anti- rheumatic drugs; DTNB: (5-5'-dithiobis [2-nitrobenzoic acid]); \\ MDA: Malondialdehyde; SOD: Superoxide dismutase; LPO: Lipid peroxidase}

\section{Acknowledgements}

Authors are thankful to the Sophisticated Instrumentation Center (SIC), Dr. Harisingh Gour Vishwavidyalaya, Sagar for sophisticated instrumentation facilities supported under DST-PURSE (II).

\section{Authors' contributions}

Both authors planned the study, designed all experiments, summarized, discussed and interpreted the results. The author(s) read and approved the final manuscript.

\section{Funding}

This research received no specific grant from any funding agency in the public, commercial or not for profit sectors. 


\section{Availability of data and materials}

All data generated or analysed during this study are included in this published article [and its supplementary information files].

\section{Ethics approval and consent to participate}

The animal ethical approval reference no.: 1413/PO/a/11.

\section{Consent for publication}

The authors have approved and consent for publication.

\section{Competing interests}

The authors report no declarations of interest.

\section{Author details}

'Faculty of Pharmacy, VNS Group of Institutions, Bhopal, Madhya Pradesh, India. ${ }^{2}$ Uttarakhand Technical University, Dehradun, Uttarakhand, India.

${ }^{3}$ Department of Pharmaceutical Sciences, Dr. Harisingh Gour Vishwavidyalaya

(A Central University), Sagar M.P.-470003, India.

Received: 27 August 2020 Accepted: 23 December 2020

Published online: 22 January 2021

\section{References}

1. Choi EM, Kim YH. A preliminary study of the effects of an extract of Ligularia fischeri leaves on type II collagen-induced arthritis in DBA/1J mice. Food Chem Toxicol. 2008:46:375e379.

2. Butler SH, Godefroy F, Besson JM, Weil-Fugazza. A limited arthritic model for chronic pain studies in the rat. Pain. 1992;48:73-81.

3. Wang $Q$, Kuang $H$, Su $Y$, Sun $Y$, Feng J, et al. Naturally derived antiinflammatory compounds from Chinese medicinal plants. J Ethnopharmacol. 2013;146:9-39.

4. Rajkapoor B, Ravichandra V, Gobinath M, Anbu J, Harikrishnan N, et al. Effect of Bauhinia variegate on complete Freund's adjuvant induced arthritis in rats. J Pharmacol Toxicol. 2007:2:465-72.

5. Xin C, Ruijing W, Peimin B, Qingke W, Vidya DDS, et al. Evaluation of antiarthritic activity of nimbolide against Freund's adjuvant induced arthritis in rats. Artif Cells Nanomed Biotechnol. 2019;47(1):3391-8.

6. Chang $X, \mathrm{He} \mathrm{H}$, Zhu L, Gao J, Wei T, et al. Protective effect of apigenin on Freund's complete adjuvant-induced arthritis in rats via inhibiting P2X7/NFkappaB pathway. Chem Biol Interact. 2015;236:41-6.

7. Lipsky PE. Rheumatoid arthritis. In: Kasper DL, Braunwald E, Fauci AS, Hauser $\mathrm{SL}$, Longo DL, Jameson JL, editors. Harrison's principles of internal medicine. 16th ed. New York: McGraw Hill; 2005. p. 1968-77.

8. Chimenti MS, Triggianese P, Conigliaro P, Candi E, Melino G, et al. The interplay between inflammation and metabolism in rheumatoid arthritis. Cell Death Dis. 2015;6:e1887.

9. Masson C. Rheumatoid anemia. Joint Bone Spine. 2011;78:131-7.

10. Beih NME, Ramadan G, Talaat RM, Ghffar EAAE. Alleviative effects of green and black tea aqueous extracts on cellular stress and anemia in rat adjuvant-induced arthritis. IJTK. 2015;14(3):335-43.

11. Ramadan G, El-Menshawy O. Protective effects of ginger turmeric rhizomes mixture on joint inflammation, atherogenesis, kidney dysfunction and other complications in a rat model of human rheumatoid arthritis. Int J Rheum Dis. 2013;16:219-29.

12. Henrotin $Y E$, Bruckner $P$, Pujol JP. The role of reactive oxygen species in homeostasis and degradation of cartilage. Osteoarthr Cartil. 2003;11:747-55.

13. Pincus T, Cutolo M. Clinical trials documenting the efficacy of low dose glucocorticoids in rheumatoid arthritis. Neuroimmunomodulation. 2015;22:46-50.

14. Valko M, Rhodes C, Moncol J, Izakovic MM, Mazur M. Free radicals, metals and antioxidants in oxidative stress-induced cancer. Chem Biol Interact. 2006;160(1):1-40.

15. Kapoor M, Martel-Pelletier J, Lajeunesse D. Pelletier JP \&Fahmi H, role of proinflammatory cytokines in the pathophysiology of osteoarthritis. Nat Rev Rheumatol. 2011;7:33-42.

16. Bakim B, Sertcelik S, Tankaya O. A case of serotonin syndrome with antidepressamnt treatment and concomitant use of the herbal remedy (Peganum harmala). Bull Clin Psychopharmacol. 2012;22(4):359-61.

17. Shatarat AT, Abuhamdah S, Alefishat E, Al-Essa M, Altaweel RR. Mohammed, $F$, et al. effects of Beta-Carboline alkaloids of Peganum Harmala on induced rat ileum Phcogj.com contractions. Pharmacog J. 2020;12(2):260-5.
18. Kim H, Sablin SO, Ramsay RR. Inhibition of monoamine oxidase a by betacarboline derivatives. Arch Biochem Biophys. 1997:337(1):137-42.

19. Trease GE, Evans IC. Textbook of Pharmacognosy. 12th edition Bailliere Tindall, London; 2008. p. 21-2.

20. Harborne JB. Phytochemical methods. 2nd ed. London: Chapman and Hall publications; 1998. p. 60-6.

21. Salvatore C, Emanuela M, Carla B, Giuseppina C, Domenico B, et al. Cloricromene, a coumarine derivative, protects against collagen-induced arthritis in Lewis rats. Br J Pharmacol. 2000;131(7):1399-407.

22. Foyet HS, Tsala DE, Bodo JCZE, Carine AN, Heroyne LT, Oben EK. Antiinflammatory and anti-arthritic activity of a methanol extract from Vitellaria paradoxa stem bark. Pharm Res. 2017;7(4):367-77.

23. Huxtable RJ. Activation and pulmonary toxicity of Pyrrolizidine alkaloids. Pharmacol Ther. 1990;47:371-89.

24. Mahajan A, Tandon VR. Antioxidants and rheumatoid arthritis. J Indian Rheumatol Assoc. 2004;12:139-42.

25. Karmakar S, Kay J, Gravallese EM. Bone damage in rheumatoid arthritis: mechanistic insights and approaches to prevention. Rheum Dis Clin N Am. 2010;36:385-404.

26. Bax M, Van HJ, Huizinga TW, Toes REM. Genetics of rheumatoid arthritis: what have we learned? Immunogenetics. 2011;63:459-66.

27. Lin B, Zhao Y, Han P, Yue W, Ma XQ, et al. Anti-arthritic activity of Xanthium strumarium L. extract on complete Freund's adjuvant induced arthritis in rats. J Ethnopharmacol. 2014:155:8248-55.

28. Tag HM, Kelany OE, Tantawy HM, Fahmy AA. Potential anti-inflammatory effect of lemon and hot pepper extracts on adjuvant-induced arthritis in mice. J Basic Appl Zool. 2014;67:149-57.

29. Ahmed S. Green tea polyphenol epigallocatechin 3-gallate in arthritis: progress and promise. Arthritis Res Ther. 2010;12:208.

30. Zhang $X$, Dong $Y$, Dong H, Zhang W, Lie F. Investigation of the effect of phlomisoside $F$ on complete Freund's adjuvant-induced arthritis. Exp Ther Med. 2017;13:710-6.

31. Rajendran R, Krishnakumar E. Anti-arthritic activity of Premna serratifolia Linn Wood against adjuvant induced arthritis. Avicenna J Med Biotechnol. 2010; 2:101-6.

32. Mondal P, Das S, Mahato K. Evaluation of anti-arthritic potential of the hydro-alcoholic extract of the stem bark of Plumeria rubra in Freund's complete adjuvant-induced arthritis in rats. IJPSR. 2016;7:3675-88.

33. Walsmith J, Roubenhoff R. Cachexia in rheumatoid arthritis. Int J Cardiol. 2002;85:89-99.

34. Kaur M, Dangi CBS, Singhai A, Singh M, Kosta S, et al. Toxicity profile of ethanolic extract of Lawsonia inermis leaves in albino wistar rats. World $J$ Pharm Pharm Sci. 2014;3(5):835-48.

35. Borah DJ. Anemia in recent onset rheumatoid arthritis. JK Science J Med Educ Res. 2007;9:120-2.

36. Bharat BA, Sahdeo P, Simone R, Ramaswamy K, Vivek R, et al. Identification of novel anti-inflammatory agents from Ayurvedic medicine for prevention of chronic diseases. Curr Drug Targets. 2011:12(11):1595-653.

37. Song SN, Iwahashi M, Tomosugi N, Uno K, Yamana J, et al. Comparative evaluations of the effects of treatment with toclizumab and TNF-alpha inhibitors on serum hepcidin anemia response and disease activity in rheumatoid arthritis patients. Arthritis Res Ther. 2013;15:R141.

38. Srivastava AK, Patil UK, Singhai A, Kumar M. Antioxidant activity of Nelumbo nucifera Gaertn stalks in rats. Int J Pharm Pharm Sci. 2015;7(3):368-73.

\section{Publisher's Note}

Springer Nature remains neutral with regard to jurisdictional claims in published maps and institutional affiliations. 